\title{
UN PUEBLO QUE DIO EJEMPLO Y MUESTRAS DE CIVILIDAD
}

\author{
Alirio Valencia Agudelo ${ }^{90}$
}

\section{RESUMEN}

De acuerdo con un convenio firmado en el año 2005 entre el Municipio de Caicedo, Antioquia y la Universidad Nacional Abierta y a Distancia (UNAD) se realizó en ese municipio del suroccidente antioqueño un trabajo de investigación tendiente a efectuar la monografía del municipio e implementar la cátedra municipal. Este trabajo se llevó a cabo mediante una metodología de investigación participativa que contó con la vinculación de la comunidad y el apoyo económico de la Secretaría de Educación departamental, a través del proyecto Mejoramiento de la calidad de la educación. El objetivo era recuperar el legado histórico del municipio con la participación de sus protagonistas y plasmarlo en un texto escrito para consulta de las presentes y futuras generaciones. En este sentido, se publicaron dos cartillas con la cátedra municipal (una para primaria y otra para bachillerato) y un libro con la monografía sobre el municipio de Caicedo, considerado el Primer Municipio no Violento de Colombia, por las muestras de civilidad que dio después de los hechos de violencia que allí se presentaron, como fue el secuestro y posterior asesinato del gobernador de Antioquia, Guillermo Gaviria Correa, y su asesor de paz, Gilberto Echeverry Mejía.

Palabras clave: transformación, no violencia, cambio social, solidaridad, libertad, dignidad.

\begin{abstract}
In accord with an agreement signed in the year 2005 between the Caicedo Municipality, Antioquia and the Open Long Distance National University (Universidad Nacional Abierta y a DistanciaUNAD) a research work was done in that municipality to the southwest of Antioquia with the aim of doing a monograph of the municipality and to implement a municipal syllabus. This work was done through a participative research methodology that counted with the involvement and economical support of the Educational State Secretariat, thorough the project Improvement of the Quality of Education (Mejoramiento de la calidad de la educación). The goal was to regain the historical legacy of the municipality, with the participation of its protagonists, and to place it in a written text form for the consultation of the present and future generations. In this sense, two books were published with the municipal syllabus (one for elementary school and a second one for middle and high school) and a book with the Caicedo Municipality's monograph, considered the First Non Violent Municipality in Colombia (Primero Municipio no Violento de Colombia), for the signs of civilized society

90 Comunicador Social. Especialista en Pedagógica para el Desarrollo Autónomo. Nació en Pueblorrico (Antioquia, Colombia). Vinculado a la UnAD desde el año 2000 como docente de la ECSAH. Ha publicado los siguientes libros: Poemas de mi tierra (1994), Pueblorrico: un pueblo en busca de su identidad (1999), Camino a la felicidad (2001), Un sueño convertido en tragedia (2007) y Monografía de Caicedo: primer Municipio no Violento de Colombia (2007). Actualmente adelanta una investigación sobre la recuperación de la memoria cultural del Municipio de Pueblorrico, Antioquia. Su correo es < aliriovalencia@yahoo.es>.
\end{abstract}


that it gave after the violence acts that occurred there, such as the kidnapping and murder of the Governor of Antioquia, Guillermo Gaviria Correa, and his peace councillor, Gilberto Echeverry Mejía.

Key words: transformation, no violence, social change, solidarity, freedom, dignity.

Recibido: 16 de marzo de 2009

Aceptado: 17 de abril de 2009

\section{INTRODUCCIÓN}

Cuando se carece de sentido de pertenencia a ese terruño donde se vive, cuando no se tiene noción de la historia de ese espacio y de ese entorno, cuando no hay conciencia del propio destino y no se tienen testimonios, entonces se habita en la nada, en algo así como un limbo existencial: no hay futuro y se hace parte del vacío, dice Reinaldo Spitaletta. Caicedo es un municipio incrustado en el suroccidente antioqueño a donde llegó gente de numerosas regiones atraída, quizá en un principio, por las inmensas riquezas auríferas y lo fértil de su tierra. Una vez allí, este conglomerado, a causa de numerosas situaciones, lucha por conquistar su identidad, por tener rasgos diferenciadores, por crear, así mismo, ámbitos amables que permitan el reconocimiento y el afecto de sus moradores. Pero este pueblo, no es sólo un área geográfica o un frío nombre, es el conjunto de voluntades que ha hecho posible pasar de la aldea lejana al próspero municipio que es hoy. Por eso, con la investigación realizada, no sólo se trata de rescatar y conservar la historia, sino de crear sentido de pertenencia por el terruño donde se nació, mejorar los espacios urbanos y rurales y crear posibilidades para todos.

Caicedo es un municipio con inmensas riquezas agrícolas, con un clima paradisíaco, con gente emprendedora y, también, con un ambiente de crisis y de pobreza, pero que, a su vez, posee ansias de cambio y una fogosa dinámica para transformarse, para autoengendrarse y renacer de las cenizas...

Puede parecer un lugar común, y es verdad: conociendo el pasado podemos caminar con mayor certidumbre hacia el porvenir, y una de las maneras de ir ganando los días que vendrán, es, precisamente, al escudriñar y estudiar la compleja realidad, no sólo para tener conciencia de ella, sino, lo que es más importante, para transformarla.

La transformación, entonces, principia en el conocimiento profundo de las raíces, en sentir el olor de la cuna y de los ancestros, en saber de dónde proceden sus habitantes, cómo vivieron los de antes en aquel pequeño poblado que antes de su fundación como municipio se llamaba El Guamo, y, en cuál fue el proceso de evolución de esa naciente aldea al hoy floreciente municipio. Y uno de los mecanismos más eficaces para comenzar a sentir arraigo, a experimentar la pertenencia a un lugar determinado, está en el conocimiento cabal del sector o vereda donde vivimos; en conocer a los vecinos; en saber cuáles son sus inquietudes, desamparos y necesidades, cuáles sus expectativas y cuáles sus conquistas. 
Es por esto que la Administración Municipal 2004-2007, en cabeza de su alcalde John Gerardo Caro Varela, quiso hacer un esfuerzo para permitir que la historia de Caicedo no quedara en el olvido, y se convirtiera en un aporte necesario y significativo al conocimiento y rescate de la historia, en la búsqueda de la identidad, que sin duda, contribuirá a aumentar el sentido de pertenencia de cada uno de los habitantes al entorno particular, a la calle, a la iglesia, a la vereda, a la plaza llena de toldos en un mercado dominical..., a la vida cotidiana.

En este sentido, en el año 2005 se firmó un convenio entre la Universidad Nacional Abierta y a Distancia (UNAD) y el Municipio de Caicedo, por valor de veinte millones de pesos (\$20 000000 ) con el fin de capacitar a la comunidad en temas relacionados con el fortalecimiento comunitario, para el diseño de la cátedra municipal y la elaboración de la monografía. Este trabajo se finalizó y presentó a la comunidad en el mes de abril de 2006. En un acto realizado con todas las instituciones educativas, los grupos organizados, los líderes comunitarios y la comunidad en general, se hizo entrega de dos cartillas (600 ejemplares): una para trabajar en los establecimientos de primaria y otra para los de bachillerato. Posteriormente, un año después, y con el apoyo del Instituto para el Desarrollo de Antioquia (IDEA), se hizo entrega de un libro con la monografía del municipio. Esta institución y la Gobernación de Antioquia se vincularon a la realización de este trabajo, toda vez que Caicedo es uno de los municipios que más ha sentido el rigor de la violencia; en la última década ha padecido tres tomas guerrilleras. Sin embargo, la población se ha sobrepuesto a todo ello, y ha merecido el título de Primer municipio noviolento de Colombia. Es de recordar que fue en este municipio donde se secuestró al gobernador de Antioquia Guillermo Gaviria Correa y a su asesor de paz Gilberto Echeverri Mejía, quienes posteriormente fueron asesinados por las Fuerzas Armadas Revolucionarias de Colombia (FARC).

\section{ANTECEDENTES Y MARCO CONCEPTUAL}

Caicedo está situado en la región del sur occidente antioqueño, es una de las regiones más ricas y fértiles de Colombia, bordea la parte más selvática del Chocó, y está asentada sobre los colosales repliegues orientales de la cordillera occidental, donde se hermanan sus veinticinco municipios cobijados por una misma cultura: la cristiandad y el café. Si en Colombia se mezcla lo bello de sus tierras y su gente, con lo feo y horroroso de su violencia, la región del suroeste antioqueño constituye una vitrina de esa tremenda dualidad. Allí parece retratado el canto de Ciro Alegría: «Más la tierra guardó su voz sanguínea, el palpitar potente de su pecho bronceado, el gran torrente de voces, gritos, balazos, cantos y agonías.»

\section{Defensores de un sueño}

A través de la historia, hombres y mujeres han practicado la filosofía de la no violencia como único recurso para enfrentarse a sus opositores y enemigos buscando, más allá de su exclusión, una transformación desde la fuerza del amor, la reconciliación y el perdón. Mahatma Gandhi en la India y Martin Luther King en Estados Unidos dejaron, para las generaciones posteriores, la esperanza de que los sueños sí pueden ser posibles. Esperanza 
que también alimentó el gobernador de Antioquia, Guillermo Gaviria Correa, al buscar la reconciliación en Colombia por medio del diálogo y la no violencia.

Mohandas Karamchand Gandhi, uno de los más importantes hombres del siglo xx, descubrió la fuerza más poderosa que ha probado la humanidad: la no violencia. Por medio de esta actitud pacífica contribuyó a descubrir la dignidad de la India, donde nació el 2 de octubre de 1869 y donde, años después, se convirtió en uno de los más respetados líderes espirituales y políticos. A través de una resistencia pacífica ayudó a la liberación de su país, el cual estuvo sometido durante más de un siglo por el Imperio de la Gran Bretaña. Por eso es honrado por su gente como el Padre de la nación India y llamado Mahatma: Alma Grande.

Gandhi estudió leyes en Londres y volvió a la India en 1891 para ejercer su profesión. En 1893 aceptó un contrato de un año para trabajar como abogado en Sudáfrica, en la época que esta era controlada por los británicos. Cuando intentó reclamar sus derechos como ciudadano inglés fue atropellado, y pronto vio que todos los hindúes sufrían idéntico tratamiento.

Veintiún años se quedó Gandhi en Sudáfrica luchando por los derechos del pueblo hindú. Desarrolló un método de acción social directa basado en los principios del coraje, la no violencia y la verdad, llamados satyagraha. Creía que el modo en que la gente se comporta vale más que lo que consiguen. Satyagraha promovía la no violencia y la desobediencia civil como los métodos más apropiados para alcanzar objetivos políticos y sociales.

En 1915, Gandhi se convirtió en el líder del Movimiento Nacionalista Hindú y desde los postulados de la satyagraha dirigió la campaña por la independencia india de Gran Bretaña. Gandhi fue arrestado muchas veces por los británicos debido a sus actividades en Sudáfrica y la India. Pasó siete años en prisión por sus actividades políticas. Más de una vez Gandhi recurrió al ayuno para impresionar a la gente sobre la necesidad de ser no violentos.

Otro de los grandes líderes que han enarbolado la bandera de la no violencia es Martín Luther King. Este pacifista, nacido en Atlanta Georgia (Estados Unidos) el 15 de enero de 1929, reunió en torno a su persona todos los rasgos que hacen posible la convivencia: diálogo, respeto, constancia, voluntad, esfuerzo, autoestima, solidaridad, tolerancia y la no violencia. A la edad de 17 años fue ordenado como maestro baptista al igual que su padre y su abuelo.

Martín Luther King se erigió como líder del movimiento en favor de los derechos civiles y su lucha fue por un trato igualitario mediante el principio de la «persuasión no violenta». En 1951 realizó su trabajo de posgrado en la Universidad de Boston y, gracias a un seminario, conoció e interiorizó los métodos de protesta pacífica de Gandhi.

Estas ideas se convirtieron en el centro de su propia filosofía de protesta no violenta, la que en 1964 le mereció el Premio Nobel de la Paz. Su famoso discurso «I have a dream» caló en los ideales de los jóvenes de todo el mundo en la década de los sesenta y sus aspiraciones de igualdad, fraternidad y respeto al contenido de la personalidad, siguen siendo hoy tarea inacabada de la humanidad. 
En el caso colombiano es el inmolado gobernador de Antioquia, Guillermo Gaviria Correa, quien dio los primeros pasos para lograr grandes cosas a través de la no violencia. Cuando Guillermo Gaviria Correa comenzó a estudiar a Gandhi y a Martín Luther King se dio cuenta de que la filosofía de la no violencia que ellos pregonaban se podía constituir en un verdadero camino para el logro de la paz en Antioquia.

Fue en la 4. ${ }^{\text {a }}$ Conferencia Mundial de la no Violencia, llevada a cabo en Rhode Island, en agosto de 2001, que el Gobernador de Antioquia entró en contacto con algunos de los más importantes líderes de este movimiento. ¿Pero qué fue lo que sedujo al gobernador sobre esta filosofía? Creemos que fue la convicción profunda de que había otras salidas diferentes a las de la guerra y la violencia. Había que ensayar otra vía. Una vía que se constituye en una forma de vida para gente valiente y comprometida en construir un mundo mejor. El camino de la no violencia.

\section{Nace el movimiento}

Fue así como la filosofía se convirtió en la base fundamental del programa de gobierno de Guillermo Gaviria Correa. Esta podía engranarse de manera perfecta en el Plan de Desarrollo: Una Antioquia Nueva 2001-2003. El movimiento en Antioquia comenzaba. Para Gaviria Correa la no violencia representaba «una filosofía que habilitaría a las personas para vivir en justicia y armonía, con el fervoroso anhelo de edificar la civilización del amor».

El dirigente tenía la firme convicción de que la no violencia era un camino posible para alcanzar el cambio social que Antioquia anhelaba. Y esta convicción lo llevó a Caicedo en una marcha para acompañar a esta población en sus acciones no violentas hacia la guerrilla de las Farc y a organizar la 5. ${ }^{\text {a }}$ Conferencia Mundial de la no Violencia en la ciudad de Medellín, la cual contó con la participación de los más destacados líderes de esta filosofía en el ámbito mundial.

Paradójicamente, el gran ausente en la conferencia fue su principal promotor, Guillermo Gaviria Correa, quien había sido retenido en el Puente del Vaho, poco antes de llegar al municipio de Caicedo.

A pesar de la ausencia del gobernador titular del Departamento, el incipiente movimiento no desfalleció, se mantuvo firme y comenzó a extenderse por todos los rincones de Antioquia: marchas, expresiones de solidaridad, entrenamiento de líderes en la filosofía de la no violencia, concentraciones por la libertad y la dignidad.

\section{Caicedo marcha por la no violencia}

A comienzos del año 2002 el municipio vivía una difícil situación. Los campesinos venían recibiendo constantes amenazas que les impedían sacar sus productos agrícolas a la ciudad de Medellín, entre ellos, el café. Esta difícil situación motivó a la comunidad, en cabeza del sacerdote José Gabriel Segura Urrego, quien lideró una campaña de resistencia civil, y tomó 
la decisión de acompañar a los campesinos para que transportaran el café, toda vez que los mismos insurgentes que una noche destruyeron el templo hoy quieren robarles su sustento económico, como lo es su cosecha cafetera.

Esta actitud lleva a Caicedo a ser reconocido como el primer municipio no violento de Antioquia, y es precisamente el gobernador Guillermo Gaviria Correa, quien encabeza una marcha de la solidaridad y de no violencia, desde la ciudad de Medellín hasta Caicedo. El gobernador y Gilberto Echeverri Mejía, Comisionado de Paz, son secuestrados por la guerrilla de las Farc, la tarde del domingo 21 de abril de 2002, en el paraje El Vaho de Anocosca, sector donde se hurtaban los camiones de café.

Este acto es repudiado por la comunidad nacional e internacional reunida en el marco de la $5 .{ }^{\mathrm{a}}$ Conferencia Mundial de no Violencia, que se realizó en la ciudad de Medellín, del 23 al 26 de abril. Varios de los conferencistas estuvieron en el sitio del secuestro y uno de ellos, Bernard Lafayette quien luchó con Martín Luther King hijo por los derechos de los afroamericanos en Estados Unidos, lo vivió personalmente, toda vez que también hizo parte del grupo de secuestrados. Este hecho ocurrió en el sector donde comenzó Caicedo su vida territorial, en la vereda de la Anocosca. Sesenta y cinco días después de su secuestro se presentaron muestras de supervivencia. El gobernador y el comisionado de paz, aparecen junto a unos militares también secuestrados; ellos pronuncian unas cortas palabras forzados por los secuestradores para decir que son declarados canjeables por subversivos presos en cárceles colombianas...

Bajo la filosofía de la no violencia, Guillermo Gaviria avanzó en la construcción de nuevas metodologías para responder de manera efectiva a la necesidad de abordar problemas complejos, en una sociedad como la antioqueña que se caracteriza por la diversidad cultural. Fue precisamente en un acto pacífico, como apoyo a la valentía de los habitantes de Caicedo y convencido de la capacidad transformadora de la no violencia, que Guillermo Gaviria, el comisionado de paz Gilberto Echeverri Mejía, obispos, activistas extranjeros, y más de mil ciudadanos, decidieron realizar la Marcha de la no violencia y la reconciliación en solidaridad con Caicedo, como una expresión de apoyo y motivación para responder a actuaciones similares en otros municipios de Antioquia, que eran asediados por la violencia de distintos grupos armados.

\section{Un hecho desafortunado}

En este acto de solidaridad, que le tomó a los marchantes cinco días de caminata y a sólo cuatro kilómetros para llegar al casco urbano de Caicedo, fueron interceptados por el frente 34 de las Farc quienes, con el pretexto de querer dialogar sobre la no violencia, se llevaban a un grupo de siete personalidades, entre ellas Bernard Lafayette hijo, director del Centro de Estudios sobre Paz y no Violencia de la Universidad de Rhode Island (EE. UU.); el obispo de Santa Fe de Antioquia, Ignacio Gómez Aristizábal; el obispo auxiliar de Medellín, Jorge Iván Castaño Rubio; Monseñor Jairo Jaramillo, de la Diócesis de Santa Rosa de Osos y el sacerdote Carlos Arturo Yépes, capellán de la Gobernación de Antioquia. Paulatinamente, los guerrilleros fueron liberando a los retenidos, pero en su poder quedaron, Guillermo y Gilberto, a quienes 
las Farc sumaron al grupo de personalidades nacionales canjeables por subversivos presos en las cárceles. Previendo como una remota posibilidad el hecho de que las Farc lo secuestraran, o incluso que lo asesinaran, el 16 de abril Guillermo Gaviria le entregó una carta a su padre con algunas indicaciones, y su esposa le decía «no diga esas cosas tan feas que usted va a volver». Yolanda (su esposa) siempre pensó que la carta no tendría ninguna utilidad porque todos iban a regresar sanos y salvos.

\section{Una marcha violentada}

La retención del señor gobernador de Antioquia y del comisionado de pazen momentos en que se dirigían al municipio de Caicedo, se convirtió en un precedente negativo al considerar que es conversando y siendo leal con la palabra empeñada como se espera resolver el conflicto armado. Los dos personajes se alejaron de la multitud que marchaba para atender la invitación a conversar, lo que significó un grave error, porque era la misma marcha el mejor escudo protector para todos sus integrantes. Luego se comprobó que las Farc habían analizado muy cuidadosamente la reacción que el gobernador podría tener en esas circunstancias.

Como pocas veces en Colombia, esta marcha pacífica resultó concurrida y de un elevado significado social, pero pasará a la historia por haber resultado detenida y atacada por los actores armados, para retener a sus principales impulsores.

La Marcha de la no Violencia y por la Reconciliación contó con el apoyo de un grupo de organizaciones sociales e instituciones públicas y privadas, e hizo parte de una campaña que alrededor del tema de la no violencia se impulsa a nivel regional. La misma busca la afirmación de la autonomía de la población civil frente a los diferentes actores armados, a tiempo que aboga por el respeto de los bienes de la población civil, como en el caso del municipio de Caicedo. Así mismo, busca avanzar en un horizonte de reconciliación entre toda la población de Antioquia y de Colombia. Otro sentido de la marcha era desarrollar procesos participativos de capacitación y formación ciudadana.

La movilización, en su aspecto operativo, se fundamentó en un sistema de organización interna. Cada persona recibía una ficha o tarjeta con el nombre de un árbol nativo de la zona que iban a recorrer; luego, las personas se agruparon de acuerdo con tales denominaciones. Con esta acción fueron germinando los bosques de ceibas, papayos, mangos y aguacates que, a su paso, llenarían de esperanza el camino.

Posteriormente, se identificaron líderes naturales y espontáneos dentro de cada bosque y se les denominaron árboles mayores que recibieron la responsabilidad de cada grupo, antes, durante y después de la marcha. Al resto de marchistas se le identificó como semillas. Cada día se realizaban reuniones entre los árboles mayores para debatir y canalizar ideas y propuestas. Pero se presentaron algunas fallas notables: poco a poco se confundió la necesaria organización y dirección de la marcha con los llamados árboles, quienes terminaron asumiendo el manejo de aspectos fundamentales de la misma. Además, no existió una coordinación política para esta actividad. 
También hubo equívocos al suponer que para las Farc una camándula era signo movilizador de opinión pública, así como al creer que el mensaje de no violencia sería comprendido y asimilado de inmediato por esa organización. Los árboles mayores se siguieron reuniendo para renovar los compromisos adquiridos y continuar con la capacitación en no violencia, con la idea de extender los principios de esta filosofía a un mayor número de personas. Luego trabajaron en una actividad que buscaba la reducción de homicidios durante la celebración del Día de la Madre.

La retención de los líderes de la marcha desató una serie de movilizaciones en todo el departamento para exigirle a la guerrilla de las Farc que los dejaran en libertad, así como una diversidad de gestiones en los ámbitos nacional e internacional con igual propósito. También, para hacerle notar al grupo subversivo el error cometido al privar de la libertad a dos impulsores de un movimiento filosófico que defiende la negociación política por la vía del diálogo, y que se opone resueltamente a la resolución del conflicto por la vía militar.

La semana siguiente a la de la marcha de solidaridad con la comunidad de Caicedo, se cumplió la 5. ${ }^{a}$ Conferencia Mundial de no Violencia que soñaba Gaviria Correa, y a cuya organización y aseguramiento de éxito había dedicado sus mejores esfuerzos. Las voces de protesta y el proceso de sensibilización sobre la no violencia tuvieron a las pocas semanas un nuevo escenario en el ámbito nacional: el Congreso de Paz y País, organizado por un colectivo de ONG. Esta sesión final se cumplió en la ciudad de Bogotá, luego de agotar una serie de sesiones a nivel regional.

\section{Caicedo ratificó ser no violento}

El sábado 5 de mayo de 2007 fue una fecha muy especial para los caicedeños. Ese día se convocó a la comunidad para que, a través de una consulta popular, dijera si estaba de acuerdo o no en que Caicedo fuera un municipio no violento. Con 3803 votos afirmativos, los habitantes ratificaron su decisión de ser el primer municipio no violento de Antioquia y del país. La proclamación pública se dio al cumplirse cuatro años de la muerte del gobernador Guillermo Gaviria y del asesor de paz Gilberto Echeverri. Ambos fueron asesinados por la guerrilla en mayo de 2003, junto con ocho miembros de la fuerza pública, en un intento de rescate en Urrao. En la consulta electoral, participaron 3865 votantes: 3803 por el sí, 50 dijeron no y 12 votos fueron nulos. Tres mil ochocientos tres (3803) votos afirmativos ratifican a Caicedo como el primer municipio no violento de Antioquia y del país. La opinión general fue reafirmada por 1713 votos de los mayores de edad contemplados por el censo electoral. En lo que el mandatario seccional, Aníbal Gaviria Correa, calificó como un día de gran alegría para el gobierno de Antioquia, Caicedo reiteró su votación por el Sí, a la no violencia. Así este municipio del occidente antioqueño reafirma su calidad de ser el primer municipio no violento de Antioquia y del país. Al respecto Gaviria Correa dijo: Que la semilla sembrada de la no violencia crezca con la mayor fertilidad. Esta proclamación pública adquiere mayor relevancia, al cumplirse cuatro años de la muerte de los gobernadores Guillermo Gaviria Correa, Gilberto Echeverri Mejía y del grupo de oficiales y suboficiales que los acompañaban, por ser este municipio donde se gestó la decisión de estos ilustres 
antioqueños de apoyar de manera irrestricta una valerosa expresión de voluntad de paz y de respeto por los derechos de los ciudadanos.

Caicedo demostró, por iniciativa propia, su voluntad de refrendar, mediante una consulta popular, una decisión que puede ser la más importante en su vida civil, de los últimos años: seguir ostentando su calidad de municipio no violento.

\section{METODOLOGÍA Y TRATAMIENTO DE DATOS}

El trabajo de investigación que se llevó a cabo en el municipio de Caicedo contó con la participación de toda la comunidad, una vez que para la recolección de la información se utilizó una metodología de Investigación Acción Participación (IAP). En un primer momento se convocó a la comunidad para socializar el proyecto. Luego se conformaron diferentes grupos por áreas de trabajo, los que recibieron la capacitación necesaria para recolectar y archivar la información. El grupo investigador realizó la sistematización necesaria y organizó el informe final. Durante el desarrollo de la investigación, constantemente hubo conversatorios con la comunidad a fin de socializar la información recibida, confrontar datos y tener la versión de diferentes fuentes, ya que fue a través de la tradición oral como se recuperó la historia del municipio.

\section{CONCLUSIONES}

Después de finalizado el trabajo en el municipio de Caicedo quedan, entre otras, las siguientes conclusiones:

Es más enriquecedor un trabajo de investigación cuando en el mismo trabajo se involucra a la comunidad investigada.

Caicedo dio muestras de civilidad, no sólo por su posición frente a los actores de la guerra, sino por su compromiso de no dejar perdida en el olvido la historia de su terruño.

Con la investigación no sólo se beneficiaron los estudiantes de los distintos planteles de educación, sino la comunidad, en general.

La UNAD, además de realizar un trabajo de investigación, llegó a una región deprimida con un buen programa de proyección social.

A la comunidad se le entregaron dos cartillas (300 ejemplares de cada una). Con la cátedra municipal para estudiantes de bachillerato, una, y otra para estudiantes de primaria.

En el año 2007 el trabajo con la monografía de Caicedo se actualizó y se publicó un libro, el cual contó con el apoyo económico del Instituto para el Desarrollo de Antioquia (IDEA) y el municipio de Caicedo. 


\section{REFERENCIAS BIBLIOGRÁFICAS}

VALENCIA, Alirio. Monografía de Caicedo: primer municipio no violento de Colombia. Medellín: Editorial L. Vieco e hijas. 2007.

Periódico El Mundo, varias ediciones.

Periódico El Colombiano, varias ediciones. 